\title{
LIAME VIVO: QUADROS DA MEMÓRIA COLETIVA, GENEALÓGICA E FAMILIAR EM ESPAÇO TERRESTRE, DE GILVAN LEMOS
}

\section{ALIVE LINK: COLLECTIVE, GENEALOGY AND FAMILY FRAMES IN ESPAÇO TERRESTRE, BY GILVAN LEMOS}

\author{
Anderson Felix dos Santos \\ Universidade Federal de Pernambuco (UFPE) ${ }^{1}$
}

\section{RESUMO}

O estudo tem como objetivo analisar as memórias genealógica e familiar como elementos estruturantes do enredo no romance Espaço Terrestre (1993), de Gilvan Lemos e sua importância para solidificação do grupo familiar. Para tanto, baseou-se na teoria dos quadros sociais da memória, que indica um conjunto de aspectos mnemônicos coletivos que caracterizam e perpetuam as memórias de um grupo.Os conceitos debatidos pelos teóricos Maurice Halbwachs (2003; 2004), Ecléa Bosi (1994), Myriam Lins deBarros (1987), entre outros, constituíram o arcabouço teórico para compreender o tema explorado.Foi possível verificar que as memórias coletiva, genealógica e familiar são elementos basilares na construção do enredo e na conservação da unidade do grupo.

PALAVRAS-CHAVE: Gilvan Lemos;Memória coletiva;Memória familiar; Memóriagenealógica.

\begin{abstract}
The study aims to analyze the family and genealogical memories as one of its structural plot elements of the Espaço Terrestre (1993) novel's, by GilvanLemos and its importance to solidifies the family group. To do this, supported on the theory of social frames of memory, which indicates a set of collective mnemonic aspects that characterize and perpetuate as memories of a group. Concepts discussed by Maurice Halbwachs (2003; 2004), EcléaBosi (1994), Myriam Lins Barros (1987), and others, comprise the theoretical set of ideas to understand the theme. It was possible to verify that the collective, genealogical and family memories are basic elements in the construction of the plot and the conservation of the group's unity.
\end{abstract}

KEYWORDS: Collective memory; Family memory; Genealogical memory;GilvanLemos.

\section{INTRODUÇÃO}

Desde os primórdios, a humanidade tem a memória como guia. Esta é seu instrumento para registrar, modificar e perpetuar o conhecimento no mundo a sua volta (CANDAU, 2016); como constatação, basta recuperar as pinturas rupestres: elas eram a necessidade de registrar os acontecimentos de uma época e de uma sociedade, de modo que eles se perpetuassem e cumprissem uma tradição que se renovaria incessantemente em cada partícipe daquela cultura. A memória, portanto, prescinde de um receptor para que exista em sua plena função, ela necessita que alguém a ative, transmita e conduza, justamente por isso, age como modeladora de identidades nas sociedades e grupos (HALBWACHS, 2003). Trata-se de um movimento ostensivo e natural: o homem vive

\footnotetext{
1 Doutorando e mestre em Teoria da Literatura pela UFPE, graduado em Licenciatura em Letras Português/Espanhol pela UPE. Este artigo apresenta um recorte da pesquisa empreendida na dissertação defendida em 2019, financiada pelo CNPq. E-mail: andersonfelixletras@gmail.com
} 
lembrando e lembra-se para viver, na interminável tentativa de construir e reconstruir elos de sua própria trajetória.

A orientação que aqui se propõe é de instrumentalização mnemônica - como é frequente que se faça - e sua relação com a Literatura para investigar as memórias genealógica e familiar como elementos estruturantes do enredo no romance Espaço Terrestre (1993), de Gilvan Lemos e sua importância para solidificação do grupo familiar dos Albanos, núcleo principal da narrativa.

O enredo desnovela-se em torno de um grupo de pessoas que, insatisfeitas com o estado de tensão que precedeu a Revolução Pernambucana de 1817, decidiram empreender um êxodo e viver em uma cidade criada por eles - de nome Sulidade - onde poderiam organizar uma nova concepção de realidade social. A figura protagonista desse êxodo é Albano Nuno Varela, que na comunidade recém constituída perpetua sua estirpe ao modo de CienAños de Soledad(1967) - os nomes se repetem e se confundem: Albano Filho, José Albano, Albano José, José Albano Neto. Esse processo genealógico conserva também a memória familiar - exclusivamente masculina, uma vez que as mulheres morrem ao dar à luz - que compõe aquele grupo. A obra apresenta os membros dessa família compartilhando recordações que se estabelecem com parte de suas identidades.

Pensando em memória como dimensão social, Halbwachs (2004) formulou a teoria de quadros sociais da memória: um conjunto de referências espaciais, temporais, sociais, entre outras, que contribuem para que seja possível recordar os acontecimentos. Tais quadros se formam nos grupos que compartilham saberes como instrumento de integração entre os sujeitos, por exemplo, os grupos religiosos, campesinos e familiares.

O autor argumenta também que todas as lembranças individuais são parte de um contexto coletivo, pois os indivíduos carregam muito dos outros dentro de si. Isso acontece em decorrência da vida em sociedade e do intercâmbio cultural entre as pessoas. Assim, toda memória individual é uma perspectiva acerca da memória coletiva, tendo em vista os pontos de importância da memória de cada sujeito serem diferentes.

Pretende-se ao longo deste trabalho demonstrar a conexão entre os conceitos apresentados e seu entendimento como chave de leitura para o romance Espaço Terrestre, considerando sua narrativa aportada na memória como instrumento coletivo, que demonstra sua dimensão social e os mecanismos de transmissão.

\section{Memória coletiva como instrumento de narrativa}

Em publicação original de 1896, Matéria e Memória, o filósofo francês Henri Bergson (2010) empreende a tentativa de analisar a realidade do espírito a partir da relação entre este e a memória. Segundo o autor, a lembrança "representa precisamente o ponto de intersecção entre o espírito e a matéria" (BERGSON, 2010, p. 5). Ciente da dualidade existente entre os objetos da tese, seu interesse é demonstrar que a recordação não é somente uma atividade mecânica e puramente fisiológica do cérebro, mas uma relação de ordem psicofisiológica que se inicia no espírito.

O pressuposto basilar de Bergson (2010) é que o cérebro integra o mundo sensível, portanto, não seria capaz de, exclusivamente ele, ser o responsável pela produção das imagens, pelo contrário, depende dos estímulos das imagens exteriores e pode modificá-las. Em outras palavras, o corpo-matéria não pode, sozinho, criar uma representação, por isso precisa ser ativada pelo espírito.

O filósofo compreende que o espírito é o dispositivo que ativa a memória e, com isso, destaca as imagens permitindo a reprodução e representação do real. Ao debruçar-se sobre o estudo da memória, é importante recorrer a Bergson porque ele foi o primeiro teórico a sugerir que a relação entre esta e cérebro não era mecânica, mas ativada por um elemento específico da essência humana. 
Entretanto, reside na teoria de Bergson uma lacuna: se a memória e a percepção estivessem, como sugere o autor, dispostas como em um cone onde o espírito ativa o dispositivo que recupera a lembrança e a faz emergir do fundo (souvenir = vir à tona), bastaria o desejo de recordar para efetivamente recordar qualquer fato, sendo necessário apenas recuperá-lo do fundo do cone através do espírito.

Em 1925, o sociólogo francês Maurice Halbwachs acrescenta uma variável fundamental ao trabalho de Bergson ao publicar sua conceituada obra LesCadresSociaux de laMémoire, onde aposta que, de fato, a memória não é mecânica, entretanto, o responsável por sua ativação é a sociedade - ao invés do espírito. Para ele, as relações sociais que os sujeitos travam, estabelecem quadros sociais nos quais as memórias se apoiam e se perpetuam. O sociólogo dedicou-se por anos a esse estudo, cujo resultado é retomado, ampliado e postumamente publicado sob o título A Memória Coletiva, onde busca estabelecer de maneira mais contundente a relação entre recordações e corpo social.

$\mathrm{Na}$ esteira de Bergson, Halbwachs (2003) destaca que a memória é usada também tanto para reforçar quanto enfraquecer nossa percepção de determinado evento. $\mathrm{Na}$ esfera testemunhal, a memória de um sujeito está compreendida entre alguém que de fato presenciou um evento e outro que certamente não esteve presente, porém gerou seu testemunho com base em experiências similares anteriores ou testemunho de terceiros.

Diante disso é possível distinguir uma lembrança individual, correspondente à interpretação de cada indivíduo que vivencia determinada experiência, mas também uma memória coletiva, que reflete a assimilação geral de um grupo de pessoas. $\mathrm{O}$ autor argumenta: "cada memória individual é um ponto de vista sobre a memória coletiva, que este ponto de vista muda segundo o lugar que ali ocupo e que esse mesmo lugar muda segundo as relações que mantenho com outros ambientes" (HALBWACHS, 2003, p. 69). Isto é, dentro da experiência coletiva, a memória individual registra de maneira particular os acontecimentos e cada sujeito terá uma percepção diferente de acordo com o lugar que ocupa em dado evento e sua relação com outros elementos internos ou externos à experiência vivida. A recordação, ao contrário do que geralmente se acredita, não é algo ligado a uma única pessoa. Cada sujeito é fruto de uma coletividade, pois a memória é uma experiência sempre partilhada.

Quando a memória de um sujeito é reforçada pela memória de terceiros, de uma maneira coletiva, onde as pessoas compartilham pontos em comum de suas memórias individuais, torna-se mais crível a exatidão de cada memória, pois é como se existisse um conjunto de recordações que se encaixam e se completam, solidificando uma única impressão. Assim, a memória coletiva tem, também, a função de corroborar e fortalecer a memória individual. O sociólogo aponta, inclusive, que outras pessoas não precisam necessariamente estar presentes em dado evento para interferirem sobre eles, pois um sujeito carrega muito dos outros dentro de si, desse modo, ao vivenciar uma experiência, o indivíduo está vivenciando-a a partir de referências prévias, compostas também por terceiros.

São também os diferentes pontos que as lembraças dos indivíduos evocam que modificam a sociedade. Em vilarejos ou pequenas cidades, a convivência se dá de tal modo que a participação dos habitantes nas vidas uns dos outros é muito intensa, portanto quando ocorre um evento, forma-se tanto uma memória coletiva, com a apreensão geral a situação; como uma memória individual, que diz respeito à maneira específica que cada pessoa interagiu com tal fato, seus pontos de vistas, interesses e subjetividades. Ao registrar esses acontecimentos, a coletividade mnemônica os perpetua e contribui para a modificação da sociedade.

Em Espaço Terrestre, pode-se verificar algumas passagens nas quais se fazem presentes os aspectos mencionados até aqui, por exemplo, quando misteriosos estrondos ocorridos em certa ocasião passaram a fazer parte da história da cidade e isso foi 
perpetuado por todos os seus habitantes, tornando-se um marco temporal, não pelo registro de um calendário, mas pela memória coletiva, de modo que os acontecimentos posteriores passaram a ser mencionados como ocorridos "antes" e "depois" dos estrondo:

Os estrondos marcaram a vila de Sulidade, serviram por muitos anos de indicadores de fatos extraordinários: foi no dia dos estrondos; aconteceu três dias antes dos estrondos; foi um mês depois dos estrondos. Qualquer referência ao ano de 1924 substituíam-se os algarismos pela lembrança e nomeação dos estrondos (LEMOS, 1993, p. 178).

A chegada de uma tropa de soldados também foi um evento que se solidificou na memória coletiva daquele povo. Os soldados deixaram na cidade não apenas objetos, como armas e munição, mas também uma marca profunda nas famílias, visto que mantiveram relações sexuais com as moças, então, meses depois, passada a tropa, em Sulidade nasceram diversos filhos sem pai conhecido.

Igualmente, depois de uma disputa com os cangaceiros que surgiram de assalto na cidade, a memória coletiva registraria e perpetuaria tal fato como marca da comunidade, que passou a se reunir posteriormente para compartilhar os seus mais variados feitos. Assim, as memórias individuais se fundiram com a coletiva, se deturpando e forjando uma história não oficial, mas que perduraria ainda mais que os registros escritos, sobretudo, devido ao grau de pessoalidade de cada habitante na aventura: "Não havia ninguém ferido, mas cada um tinha lambanças a contar" (LEMOS, 1993, p. 227). Em outro trecho, narra-se: "Dias depois foram-se descobrindo mais histórias curiosas. A população em peso de Sulidade reunia-se debaixo da gameleira para gozá-las" (LEMOS, 1993, p. 228).

Da mesma maneira, o esquecimento progressivo das memórias coletivas pode contribuir, para o fim de costumes e tradições, dado que são os cidadãos que os mantêm, como sugere o sociólogo: "a memória de uma sociedade se estende até onde pode - quer dizer, até onde atinge a memória dos grupos de que ela se compõe" (HALBWACHS, 2003, p. 105). A citação anterior relaciona-se justamente com a capacidade das reminiscências de um grupo contribuir para perpetuação de sua história, enquanto houver memória, a comunidade sobrevive.

Um sujeito passaa viver determinado evento influenciado direta ou indiretamente por outras pessoas. Quanto a isso, o autor posiciona-se da seguinte maneira:

\footnotetext{
Quando um homem entra em sua casa sem estar acompanhado por ninguém, sem dúvida durante algum tempo ele 'andou só', na linguagem corrente - mas ele esteve sozinho apenas em aparência, pois, mesmo nesse intervalo, seus pensamentos e seus atos se explicam por sua natureza de ser social e porque ele não deixou sequer por um instante de estar encerrado em alguma sociedade (HALBWACHS, 2003, p. 42).
}

Como observado pelo sociólogo, a memória permite a localização dos sujeitos em um contexto. Tomando como base seu argumento, é possível verificar que o mesmo conceito de memória como instrumento social, aparece em Espaço Terrestre. Ao fundar Sulidade, cidade onde residirão dali por diante, é a memória coletiva que perpetua a tradição, os costumes e a história das famílias ali refugiadas, funcionando como um liame vivo capaz de manter a unidade do grupo.

No caso das passagens expostas aqui, as personagens estão impelidas a criar um relato heroico de suas façanhas e, portanto, contaminadas pela vontade de construir uma narrativa hiperbólica dos acontecimentos. Pode-se observar por meios desses fragmentos como a memória individual negocia com a coletiva, para compor a narrativa. 


\title{
Quadros sociais da memória genealógica e familiar
}

EmLesCadresSociaux de laMémoire, Halbwachs (2004) trabalhou com a teoria de quadros sociais da memória. Trata-se de um conjunto de referências espaciais, temporais, sociais, entre outras, que contribuem para que seja possível recordar, deliberadamente ou não, os acontecimentos do passado. Segundo ele, o desaparecimento ou transformações desses quadros implicaria no desaparecimento e transformação das lembranças.

De acordo com o sociólogo, é natural que os adultos percam o interesse no passado, afinal, estão compondo quadros de novos tempos. $\mathrm{Na}$ velhice, ao contrário, existe disponibilidade, condições e um desejo quase nostálgico de recuperar os momentos da juventude, sobretudo da infância. É de se esperar, portanto, que nos núcleos familiares exista uma conexão quase mnemônica entre avós e netos, sendo estes os responsáveis por ativar as lembranças que estiveram sempre presentes nos idosos, embora afastada progressivamente por diversos fatores do presente:

\begin{abstract}
Parece bastante natural que os adultos, absorvidos por suas preocupações atuais, percam o interesse por tudo que, no passado, não se conecte. Não é porque precisamente se deformam suas recordações de infância que são obrigados a entrar nos quadros do presente? Porém não é o caso dos anciãos. Estes, cansados da ação, se desviam ao contrário do presente, e se encontram nas condições mais favoráveis para que os acontecimentos passados reapareçam tal como tiveram lugar: Entretanto, se reaparecem, é porque estiveram sempre aí.Não é uma prova flagrante da conservação de lembranças que acreditávamos suprimidas? (HALBWACHS, 2004 p. 127, tradução minha). ${ }^{2}$
\end{abstract}

Decorre disso o interesse maior dos velhos pelo passado, nesse caso, a memória não é somente um ato imaginativo, mas um exercício intencional de despertar a lembrança do que foi vivido. Precisamente por isso os velhos se ocupam de recorrer a registros, documentos, diálogos com pessoas que conviveram no passado, bem como se ocupam em compartilhá-lo. Com a renovação do interesse pelo passado na velhice, constata-se que a memória sempre esteve latente. Evidentemente, isso não significa que ele tem mais capacidade cognitiva de rememoração na velhice do que na mocidade, mas que, uma vez ancião, se preocupa com a manutenção da atividade mnemônica.

Nesse sentido, muito do passado remoto é transferido para as pessoas por intermédio de seus pais e avós. $\mathrm{O}$ autor esclarece isso por meio do exemplo das sociedades rurais como a retratada no romance Espaço Terrestre; nesse contexto, observa-se que os pais, ocupados com os trabalhos no campo, confiam a guarda das crianças aos velhos. Esses, por sua vez, tornam-se responsáveis pela transmissão da cultura e do passado por meio das crianças, tal como ocorre na narrativa diante da relação entre os Albanos avôs e seus netos. Os avós resguardam uma memória de uma época diferente que é transmitido concomitantemente com o desenvolvimento da criança em um período de novas tradições, é um encontro de gerações onde a mais nova absorve muito do contato com a mais velha. Trata-se de uma memória de estirpe que se perpetua, servindo de princípio organizador da memória de um indivíduo.

\footnotetext{
${ }^{2}$ Naedição consultada: Parece bastante natural que los adultos, absorbidos por sus preocupaciones actuales, pierdan interés por todo lo que, en el pasado, no se conecte. Si deforman sus recuerdos de infancia, ¿no es precisamente porque los obligan a entrar en los marcos del presente? Pero no es el caso de los ancianos. Estos, cansados de la acción, se desvían al contrario del presente, y se encuentran en las condiciones más favorables para que los acontecimientos pasados reaparezcan tal cual tuvieron lugar: Pero, si reaparecen, es porque estaban siempre allí. ¿No es una prueba flagrante de la conservación de recuerdos que podíamos creer suprimidos?
} 
O princípio de transmissão de memória pelos mais velhos, sobretudo os avós, nas comunidades rurais ocorre também nas sociedades primitivas, onde os anciões são os guardiões da história da sociedade, como observa o autor:

\begin{abstract}
Nas tribos primitivas, os idosos são os guardiões das tradições, não somente porque as receberam mais cedo que os demais, também porque dispõem, sem dúvida, do tempo livre necessário para transmitir os detalhes no decorrer de encontros com os demais anciãos, e para ensiná-las aos jovens a partir da iniciação. Em nossas sociedades também se estima um ancião pelo motivo de que, tendo vivido durante longo tempo, conta com muita experiência e têm um acúmulo de recordações(HALBWACHS, 2004, p. 129, tradução minha). ${ }^{3}$
\end{abstract}

Por ser um instrumento social, em muitos dos casos, a memória está intimamente ligada à família, pois seus membros compartilham do mesmo passado. Diversas experiências pessoais de um indivíduo se desenvolvem no contexto familiar, balizada pelos pais ou avós. Durante a infância, a família é o grupo com o qual a criança encontra mais contato, participando ativa e intimamente dela, assim, construindo saberes e memórias. Ainda quando separada, geográfica ou temporalmente, ela continuará fazendo parte do indivíduo, de maneira que ele a confronta e a dirige, chefe de um conjunto de memórias familiares.

Em seu estudo, o sociólogo arrola o caso das crianças em fase escolar. Ao chegarem à escola, elas desenvolvem laços diversos com outras crianças, professores, funcionários, entre outros; mas sua memória já é povoada por outras relações anteriores adquiridas no seio da família. Outro exemplo elencado é da relação mnemônica atrelada ao matrimônio: ao casar-se uma jovem da antiga sociedade grega ou romana, devia iniciar-se em todas as tradições do novo grupo. Evidentemente, as lembranças do núcleo familiar da qual descende continuam gravadas em si, mas ela acaba por adaptar-se aos novos costumes que lhe são impostos.

Assim, assume-se que é a memória genealógica que organiza a noção de família, tanto que os laços sanguíneos não são os únicos meios para se considerar membro de determinada estirpe. Ela é responsável por conduzir o sentimento de pertencimento que só se justifica, segundo Halbwachs (2004), por ele mesmo. É, também, o método de assegurar a coesão e continuidade de dada família, compondo um grupo ordenado de memórias que se perpetuam.

Pensando nas personagens de Espaço Terrestre, salta aos olhos a configuração da memória como recurso de localização dessas personagens dentro de um cosmos com ordem própria, que é a cidade de Sulidade, e como essas personagens desenvolvem pela memória um liame mnemônico que organiza a família ou uma família que é organizada por ele.

Segundo Ecléa Bosi (1994), professora e psicóloga brasileira, deter-se em análise sobre as memórias dos velhos é significativo porque as histórias dessas personalidades estão mais desenvolvidas, evidentemente, pelo trajeto de vida que percorreram. Os velhos viveram a vida em diferentes organizações individuais, de sociedade e de grupos, assim a memória social registrou um período e variedade maiores de acontecimentos. Além disso, ao evocar as lembranças, o velho está reivindicando e perscrutando seu passado e sua história.

${ }^{3}$ Naedição consultada: En las tribus primitivas, los ancianos son los guardianes de las tradiciones, no solamente porque las han recibido más temprano que los demás, también porque disponen sin duda del tiempo libre necesario para transmitir los detalles en el curso de entrevistas con los demás ancianos, y para enseñarlas a los jóvenes a partir de la iniciación. En nuestras sociedades también se estima a un anciano en razón de lo que habiendo vivido durante largo tiempo cuenta con mucha experiencia y tiene un cúmulo de recuerdos.

Revista do GELNE, Natal/RN, Vol. 22 - Número 2: p. 52-62. 2020 
Seria o velho também responsável pela transmissão e alteração da memória familiar, dos grupos sociais, das instituições e da sociedade. A proximidade com o fim da vida e a perda da maioria das referências, faz com que eles intensifiquem o contato com as novas gerações e sejam impelidos pela necessidade de fazer retrospectivas saudosas de seu passado. Por conseguinte, como a memória individual sozinha não é suficiente para o reconhecimento de lembranças, uma vez que prescinde de pontos em comum com a memória coletiva de uma sociedade ou grupo, os mais velhos são os pontos de interseção entre as mais diversas memórias e tradições de uma família.

A modificação da história familiar pode ocorrer porque as percepções, em contato com as memórias de outros indivíduos ao longo da vida, se alteram, se deslocam e se misturam. De tal modo que, por muitas vezes, a memória coletiva se confunde com a individual, confrontando-a ou apoiando-a, como descreve a autora:

É preciso reconhecer que muitas de nossas lembranças, ou mesmo de nossas ideias, não são originais: foram inspiradas nas conversas com os outros. Com o correr do tempo, elas passam a ter uma história dentro da gente, acompanham nossa vida e são enriquecidas por experiências e embates. Parecem tão nossas que ficaríamos surpresos se nos dissessem o seu ponto exato de entrada em nossa vida. Elas foram formuladas por outrem, e nós, simplesmente, as incorporamos ao nosso cabedal. Na maioria dos casos creio que este não seja um processo consciente (BOSI, 1994, p. 406, grifos da autora).

Portanto, as memórias dos indivíduos podem se modificar ao longo do tempo, em decorrência das novas informações que se adquire, dos estímulos, reforços ou percepções que cada sujeito recebe ao longo de sua vida, corroborando com o argumento de Halbwachs (2003).

A importância da transmissão de saberes na relação avós e netos é retratada pela pesquisadora Myriam Moraes Lins de Barros (1987) em Autoridade e Afeto, trabalho de campo no qual propõe um retrato das formações e estruturas das famílias brasileiras, partindo. Em meio ao levantamento dos dados, é possível perceber que os próprios entrevistados frequentemente situam as histórias de suas vidas a partir das trajetórias de seus ascendentes, alguns deles afirmando que para falar de si, precisam retomar a história de seus avós.

As lembranças de uma estirpe são recorrentes, principalmente, quando pensadas no contexto da infância, tema que desponta para explicações e associações sobre o próprio indivíduo que narra. A presença dos avós está até mesmo na ausência, quando, por exemplo, os netos não os conheceram, mas passam a atuar junto a seus próprios netos para compensar essa falta, suprindo neles desejos ou necessidades que os próprios tiveram. Existe então uma confluência dessas vivências, como a autora observa:

A narração da história de vida realça a importância não apenas da relação dual entre avô (avó) e neto (a) vivida hoje pelos entrevistados, como também das relações familiares estabelecidas ao longo de toda a vida, que favoreceram a socialização desses indivíduos nos papéis que atualmente desempenham na família (LINS DE BARROS, 1987, p. 74).

É relevante registrar que a relação entre família e memória, compondo o liame vivo conceituado como memória genealógica e familiar, é a realização mnemônica enquanto objeto e espaço ao mesmo tempo, ou seja, é o objeto de recordação, mas também o lugar de avivamento das lembranças. Tal procedimento é, de certo modo, a delimitação do tempo e do espaço pelo indivíduo por meio da memória, pelo ponto de vista de sua memória individual, dentro de um contexto coletivo. 
Se o limite da memória é o mesmo do indivíduo, se a lembrança do sujeito é o limite do grupo social, a sobrevivência somente será possível através da perpetuação das identidades de maneira coletiva e atávica, daí a importância de uma memória genealógica e familiar: ela é a ferramenta que conserva e permite, com atualizações, que o grupo não se desintegre, operando pela manutenção da estirpe e, consequentemente, da comunidade na qual está inserida. Essas memórias são vivas, se transformam por meio da reconstrução do passado, uma reconstrução que não é sempre precisa, considerando que é feita no presente, com olhares e sensibilidades já modificados pelo tempo.

No romance em análise, o avô é agente transmissor de cultura, de trabalho, de educação para o sagrado, de instrução climática, de tradições e costumes, apresentando-se inclusive como fonte de história - tanto a oficial, quanto do vilarejo e da família - como se comprova com o excerto a seguir:

Do avô José Albano, com quem mais convivia, é que José Albano Neto ganhava os conhecimentos: da labuta no campo, das mudanças do tempo, das desgraças, das intempéries, do louvor à bonança, da conformação ao sofrimento, das imposições da vida e da inutilidade da luta inglória contra o que já estava traçado por um Ser invisível que não chamava de Deus, mas que, ao referir-se a Ele, erguia os olhos ou apontava o céu com indicador rústico, apocalíptico, de determinação imemorial. Do avô, que igualmente convivera com todos os Albanos conhecidos e a todos ouvirá é que José Albano Neto apreendida as histórias da família e de Sulidade, as que provavelmente teriam acontecido. Histórias não documentadas, não contadas em livros, sujeitas portanto a interpretações pessoais, diminuições ou acréscimos próprios de narrativas que por muito repetidas vão-se deturpando naturalmente. Não obstante, para José Albano Neto o avô era o centro de tudo que dizia respeito a Sulidade e a família Nuno Varela, o avô era sábio (LEMOS, 1993, p. 13-14).

É importante perceber como se dá a transmissão da memória entre esse núcleo familiar: as características passadas entre avôs e netos são mais intensas, ainda que eles não tenham se conhecido, do que as passadas de pai para filho. As características dos Albanos se repetem como princípio atávico, fazendo com que frequentemente o neto pareça com o avô, compartilhando não apenas as características físicas, marca de todos os Albanos, como a cor dos cabelos, dos olhos e a ausência de jenipapo nas nádegas ${ }^{4}$, mas também interesses intelectuais, culturais e inspirações de vida, como se observa no excerto que segue:

\begin{abstract}
Quanto a ser louro, de olhos claros, não havia discordância. Os Albanos eram todos louros e de olhos claros. José Albano Neto, diante do que ia aprendendo ou descobrindo, achava, sem revelar ao avô, que mesmo assim não tivessem sido assim tê-los-ia classificado, porque na verdade tais atributos, ao correr dos anos, principalmente agora, que Sulidade se descaracterizava, constituíam a maior glória e o constante orgulho dos Albanos. Tanto que quando se referiam a um deles, aos dois anteriores que José Albano Neto não conheceu, concluíam, sentenciosos: Era louro de olhos azuis (LEMOS, 1993, p. 15).
\end{abstract}

Quando os avôs e netos não convivem diretamente, a transmissão é intermediada pelo pai, então a memória do núcleo familiar continua desenvolvendo-se. A relação entre José Albano e Albano Nuno Varela, por exemplo, sobrevive por intermédio do pai, como se comprova pelo trecho a seguir, do discurso do narrador:

Passou a criar José Albano como ele próprio fora criado pelo pai, da mesma maneira como o pai fora criado pelo avô. Nas horas de lazer pegava-o nos braços, montava no cavalo e ganhava as lonjuras dos ventos livres. Enfaixava o

\footnotetext{
${ }^{4}$ Chama-se "jenipapo" uma marca de nascença nas nádegas ou cintura que, segundo algumas crenças, indicam traços de mestiçagem. A palavra aparece no livro Casa Grande e Senzala, de Gilberto Freyre e é reproduzida por Gilvan Lemos.
} 
menino pela cintura, as costas dele contra sua barriga, acomodava-o no arção da sela, e era como se o nutrisse de novo, continuasse em outra fase a que a mãe iniciara, transmitisse-lhe diferentes energias de desenvolvimento e mais se ligava a ele (LEMOS, 1933, p. 146-147).

É possível perceber que, enquanto preceptor do neto, opera-se uma intensificação do laço familiar, em uma transmissão benéfica para ambos, ativando, ao mesmo tempo, recordações do avô e instrução para o menino, estabelecendo uma educação informal conduzida pelo afeto e pela partilha mnemônica. Em outra passagem do romance, essa transmissão aparece ainda mais claramente:

\begin{abstract}
Albano José puxara ao avô Albano Filho gostava de ler, fazer longas viagens sem sair do lugar. Um sonhador, sempre pegado com os livros que professor Sarinho lhe emprestava. Livros de folhas amarradas, catingando mofo e mijo de rato. Naquela idade era um danado na história, na geografia, na gramática. Como Albano Filho, pai de José Albano e avô de Albano José. Tanto Albano seguido até fazia a gente se atrapalhar. Mas no caráter, nas maneiras, não se confundiam, antes de completavam, havendo curiosa transferência de identidade não de pai para filho mas de avô para neto. Ele, por exemplo, achava-se parecido com o avô Albano Nuno Varela, enquanto o filho Albano José se inclinava mais às tendências de Albano Filho seu avô, dele, Albano José (LEMOS, 1993, p. 167).
\end{abstract}

Observa-se que no romance, o processo de transmissão de memória surge até mesmo na repetição dos nomes das personagens do grupo familiar principal. O batismo perpetua de maneira cíclica a identidade dos Albanos por quatro gerações: Albano Filho, José Albano, Albano José, José Albano Neto. Não se registra no romance um batismo cristão, com águas e padres, mas um batismo de nome patrilinear, que indica uma tradição. A repetição desse nome significa a tentativa de dar unidade a uma memória familiar. Por outro lado, é também uma maneira de evitar o esquecimento, pois é ostensivamente a reinvindicação da genealogia.

Por meio das personagens transmite-se tanto as recordações e a história quanto as características físicas, é uma perpetuaçãocultural e genética. A memória se organiza de acordo com um princípio atávico que se direciona como um elo entre as gerações, desde os gestos e tradições mais simples até a noção de unidade entre a família dos Albanos.

José Albano Neto, no entanto, verificava que os dedos dos seus pés se friccionavam da mesma maneira de ontem, de anteontem e de anos atrás, obedecendo-lhe a vontade, dele, José Albano Neto, que desse modo ancestral assim o pai, assim o avô - espantava a preguiça mal desperta à jornada de trabalho; que seus olhos então piscavam com a mesma indolência e desinteresse, a enxergar objetos, reais ou imaginários (LEMOS, 1993, p. 10).

De certo modo, é como se ao longo de todos os anos a memória genealógica e familiar tenha forjado o mesmo Albano, diluído em muitos, que reivindicam a história de seu povo, de sua cidade e, sobretudo, ostensivamente empunham a memória como armas para existirem como cidadãos no presente, ligados por um sentimento único.

Todo avô já o é antes do nascimento do neto, visto que já experimentaram eles mesmos serem netos e estabeleceram uma relação com seus próprios avôs. Do mesmo modo, um filho poderá sempre ocupar qualquer função na sociedade ou jamais conhecer seu pai, mas jamais deixará de ser um filho. A relação genealógica é, portanto, irreversível. E como são os avôs os principais transmissores das memórias genealógicas e familiar, quando estes morrem, permanecem ativos nas memórias dos netos, que lhes restituem significados.

O núcleo familiar encontra-se submetido a um tempo cíclico, conduzido pela memória genealógica e familiar, onde os Albanos se repetem indefinidamente. Esse ciclo se 
estende repetidamente na confluência de características entre avôs e netos, na perda das esposas após o parto, na vontade de conhecer restante do Brasil que foi abandonado na diáspora, no temperamento, entre outros elementos. Perpetuada pela tendência mnemônica da memória, o primeiro Albano sempre retorna:

\footnotetext{
Voltava no neto de antiga parceria, de consciência afetuosa, de ensinamentos e aprendizados mútuos, os extremos que embora paralelos sempre se encontravam. Tudo que era seu fora seu, nele se concentrava, sólido como a dureza dos maus tempos. Em todos os Albano, como o pai lhe dizia repetidamente, o avô José Albano se resumia, firmava história, se eternizava, como fora seu desejo (LEMOS, 1993, p. 260).
}

O sentimento que guia o grupo dos Albanos transcende os limites da vida, uma vez que na memória reside a capacidade de perpetuar o significado de uma pessoa mesmo depois de falecida. Isso pode ser observado na estreita relação entre os Albanos avôs e netos, de modo que quando um falece, continua presente no outro, como verifica-se no episódio a seguir, de uma passagem na qual José Albano passa por uma dificuldade e acredita estar sendo protegido pelo avô:

Ou talvez o avô, donde estivesse, dedicava-se então a protegê-lo, a ele, José Albano. Nada comentou com o pai, mas sorriu enternecido, certo de que ainda contava com os favores de Albano Nuno Varela, seu avô (LEMOS, 1993, p. 115).

Essa mesma memória é como um fio condutor da vida, pois as personagens sobrevivem por meio delas. Observa-se, portanto, que recordar é, não somente fazer vir à tona suas lembranças (sowvenir, de Bergson), mas reativá-las por meio das relações que foram travadas com outros indivíduos e em outros quadros permitindo sua atuação na formação dos sujeitos.

\section{CONSIDERAÇÕES FINAIS}

Há quase um século, Maurice Halbwachs, seguindo uma tradição fundada em Henri Bergson, promoveu o entendimento da memória como um fator eminentemente social, transmitido por meio da interação dos sujeitos. Halbwachs $(2003 ; 2004)$ entende memória como algo coletivamente construído, portanto, fruto das relações sociais dos indivíduos com suas respectivas comunidades. Ele aposta que não existe memória sem sociedade, portanto, é uma ferramenta ostensiva e social.

Essas relações seriam ainda mais acentuadas em contextos onde o grupo compartilha raízes e interesses semelhantes como os grupos religiosos, comunidades rurais e famílias, estabelecendo-se assim quadros sociais que serviriam de referência para a projeção das memórias e sua perpetuação. Os conceitos do sociólogo oferecem uma chave de leitura para Espaço Terrestre, visto que no romance, as personagens perpetuam suas tradições por meio da genealogia, sendo a recordação o elemento primordial para compor o enredo.

Confirmado o caráter social da memória,pode-se localizá-la dentro de determinados grupos onde os marcos sociais são mais acentuados, como é o caso do grupo familiar. As memórias genealógica e familiar se desenvolvem nesses grupos e modo mais profundo, pois os membros de uma família compartilham de um passado comum. A capacidade de recordar está diretamente ligada às relações humanas, sendo o seio familiar a primeira interação da criança com outras pessoas, ou seja, está sempre apoiada em um contexto coletivo. 
A adjetivação da memória como algo social, como o fez Halbwachs na sociologia e Gilvan Lemos no romance, demonstra sua dimensão e os mecanismos de transmissão isto é, os quadros que as compõem. Dentre eles, a intermediação mnemônica da família e da genealogia na construção das identidades dos sujeitos.

Tanto no romance quanto nas teorias estabelecidas pelos estudiosos arrolados, fica evidente a importância da memória dos avós para a conservação da unidade familiar. Os momentos de socialização onde os mais velhos estão em contato com os demais membros do grupo familiar, proporciona aprendizado e transmissão, em um quase ritual de introdução na vida em sociedade e no mundo adulto, que se tornam presentes não apenas para o ouvinte imediato, mas também para cada membro vindouro. É essa estreita transmissão que a obra de Gilvan Lemos enaltece por meio dos Albanos.

Asmemórias genealógica e a familiar são, portanto, irreversíveis, um filho pode ocupar qualquer função social, mas jamais deixará de sê-lo. De igual modo, jamais será um pai sem que constitua, ele mesmo, uma família (Halbwachs, 2004). Nesse caso, a memória é responsável por essa perpetuação de identidades, pois toda família é um microcosmos do mundo. Nesse sentido, a família é uma comunidade que não compartilha somente traços biológicos - como os fenótipos dos Albanos - mas está ligada por outras características subjetivas, como as do plano comportamental, afetivo e de linguagem - como a repetição da personalidade entre os Albanos avôs e netos.

Diante do exposto, pode-se concluir que as memórias genealógica e familiar são elementos fundamentais na construção do enredo de Espaço Terrestre. Este não existiria se não houvesse a transmissão mnemônica geracional, visto que é a memória que perpetua as características das personagens principais, funcionando como um elo que faça de todo Albano o mesmo.

\section{REFERÊNCIAS}

BERGSON, Henri. Matéria e memória: ensaio sobre a relação do corpo com o espírito. São Paulo: EMF Martins Fontes, 2010.

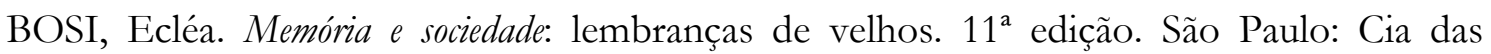
Letras, 1994.

CANDAU, Joël. Memória e identidade. São Paulo: Contexto, 2016.

HALBWACHS, M. A memória coletiva. São Paulo: Centauro, 2003.

Los marcos sociales de lamemoria. Barcelona: Anthropos, 2004.

LEMOS, Gilvan. Espaço terrestre. 1ª edição. Recife: Civilização Brasileira, 1993.

LINS DE BARROS, Myriam Moraes. Autoridade e afeto: avós filhos e netos na família brasileira. Rio de Janeiro: Jorge Zahar Editor, 1987.

Submetido em 26/03/2020

Aceito em 26/05/2020 